\title{
Photovoltaic Cooling Utilizing Phase Change Materials
}

\author{
Suhil Kiwan ${ }^{a}$, Hisham $\mathrm{Ahmad}^{a}$, Ammar Alkhalidi $^{b}$, Wahib O Wahib ${ }^{c}$, Wael Al-Kouz ${ }^{d *}$ \\ a Jordan University of Science and Technology, Mechanical Engineering Department, Irbid, 221110, Jordan \\ ${ }^{\mathrm{b}}$ German Jordanian University, Energy Engineering Department, Amman, Jordan \\ ${ }^{c}$ German Jordanian University, Department of Mechanical and Maintenance Engineering, Amman, Jordan \\ ${ }^{\mathrm{d}}$ Prince Mohammad Bin Fahd University, Mechanical Engineering Department, Al Khobar, Kingdom of Saudi Arabia
}

\begin{abstract}
A theoretical analysis based on mathematical formulations and experimental test to a photovoltaic system cooled by Phase Change Material (PCM) is carried out and documented. The PCM is attached to the back of the PV panel to control the temperature of cells in the PV panel. The experimental tests were done to solar systems with and without using PCM for comparison purposes. A PCM of paraffin graphite panels of thickness 15 $\mathrm{mm}$ has covered the back of the panel. This layer was covered with an aluminum sheet fixed tightly to the panel frame. In the experimental test, it was found that when the average cell temperature exceeds the melting point temperature of the PCM, the efficiency of the system increases. However, when the cell temperature did not exceed the melting temperature of the PCM, the use of the PCM will affect negatively the system efficiency.
\end{abstract}

\section{Introduction}

It has been denoted in many kinds of research that elevated temperatures and damp weather affect negatively on the PV performance. Ambient air temperature, solar irradiance, and wind speed are parameters that affect PV module temperature [1]. Many techniques are used in order to reduce the PV temperature; water for cooling the PV panel, refrigerant, air and using PCM. Each method has its advantages and disadvantages. Huang et al. [2] used phase change material (RT25) with internal fins to control the temperature rise of the PV system. They installed PCM with internal fins and studied the thermal performance of different internal fins arrangements. They found that when the ambient temperature was $23{ }^{\circ} \mathrm{C}$, installing PCM in the PV system decreases the cell temperature under $29{ }^{\circ} \mathrm{C}$. Brinkworth [3] tested air cooling using a ducting system underneath the PV panels for cooling an array of PV panels. They found that the optimum duct geometry for PV cooling is when duct length (L) to depth (D) ratio is in the range of (17-22) and for wide ducts, the $L \backslash D$ ratio must be 40 . Park et al. [4] investigated the electrical and thermal performance of a semi-transparent PV module in the BIPV system. The results showed that for every $1\left({ }^{\circ} \mathrm{C}\right)$ increase in $\mathrm{PV}$ temperature, the power decreases about $0.48 \%$ as compared to the standard test condition, and $0.52 \%$ in the outdoor conditions, under $500 \mathrm{~W} / \mathrm{m}^{2}$. Yun et al. [5] made a theoretical study of a ventilated photovoltaic

\footnotetext{
* Corresponding author: walkouz@pmu.edu.sa
}

façade. This module works as a pre-heating device in winter and a natural ventilation system in summer and reduces the PV temperature in both cases. The analysis showed that the overall energy performance in the narrow building was more advantageous than a deeper building. However, they concluded that installing an air gap behind the PV modules was a very important action to prevent PV failure as the temperature rises especially in summer. Solanki et al. [6] designed a new PV module with $\mathrm{V}$-trough shape metal sheets to enhance the heat dissipation and to concentrate the sunlight on the solar cells. Krauter [7] aimed to reduce the reflection as many researchers proposed as compared to expensive techniques. He suggested cooling by a film of water that reduces the temperature of the PV array, reduces reflection and keeps the surface clean. In Krauter experimental study water pumped by a low-cost pump (14\% efficiency) from the lower large tank to upper small tank at $2 \mathrm{~L} / \mathrm{min}$ pumping rate, using 12 nozzles spread along the surface which made the water film thickness of about $1 \mathrm{~mm}$. Comparing the temperature of this system with the traditional one shows $22{ }^{\circ} \mathrm{C}$ temperature reduction which is great to accomplish because the improved electrical energy of $10.3 \%$ was achieved. Water flow had improved the optical performance by $1.5 \%$ which was less than the theoretical 3\% expected. Kordzadeh [8] conducted an experimental study on a PV array cooling similar to Krauter's system, the study was about the effect of the nominal power of the array and system head on the PV water pumping. The results agree with Krauter's study 
about decreasing reflection losses based on the incidence of solar radiation angle and surface array quality. Cells temperature reduction exceeds $25{ }^{\circ} \mathrm{C}$ at noon, so the pumping flow rate reaches maximum levels at noon. Spraying the water by pumping system also leads to enhance optical losses due to reflection and decreases the cell temperature. Abdulzadeh et al. [9] tested a $225 \mathrm{~W}$ photovoltaic water pumping system experimentally, results showed that the mean PV cell efficiency increased by $3.26 \%$ and the overall efficiency increased by $1.35 \%$. Alkhalidi et al. [10] investigated the use of repurposed material utilization for environmental protection and the reduction of overheat power losses in PV panels. Where PV panel was fitted with heat dissipating fins and measured under identical test parameters; thereafter, repurposed materials such as high-density polyethylene (HDPE) and plastic bags were, separately, added to the PV panel with fitted heat-extraction fins and the performance was evaluated again. Passively cooling the PV panel with fins and repurposed materials resulted in a $22.7 \%$ drop in the PV panel's temperature, while an $11.6 \%$ increase in power output occurred at $1000 \mathrm{Wm}^{-2}$.

Al-Nimer et al. [11] investigated a novel hybrid photovoltaic/thermoelectric cooler (PV/TEC) distillation system that has been introduced. The limitation for the distillation system working under hot arid climate is the heat removal required for the condensation process from PV panels. The novelty of the proposed system is that it utilizes TEC to improve the condensation process.

$\mathrm{Li}$ Zhu et al. [12] used liquid-immersed cooling technology to eliminate the contact thermal resistance of back cooling to improve cell performance. DI water (also known as demineralized water) was used as an immersion medium for its good properties. The concentrated PV system mainly consists of a tracking dish concentrator, which was enhanced to unify a fixed light on mirror faces. Kiwan et al. [13] used a water jet to cool the PVC pipe. As mentioned by Alkhalidi et al. [14] passive cooling of PV panels helps to archive the sustainable city design.

Additionally, Al-Kouz et al. investigated the effect of dust on the PV system performance in Zarqa, Jordan and Al-Khobar, Saudi Arabia [15-16]. They found out that the dust decreases the performance of such systems. Also, Al-Bashir et al. [17] investigated the effects of solar irradiance, wind velocity and the ambient temperature on PV systems, they proposed a correlation of the PV out power as a function of the investigated parameters.

The main objectives of this work are to establish a theoretical performance analysis of the PV system, compare the theoretical results with outdoor experimental test measurements, and study experimentally the effect using PCM on both the efficiency and on the power output of the system. To achieve these goals, paraffin graphite (PCM 47) is used to do the cooling for the photovoltaic panel. This material has the advantage of having good thermal conductivity.

\section{Methodology}

An experimental investigation is done for two identical PV panels set aside in the outdoor. The PCM was added to one panel only. Temperatures, energy production from both panels are measured and the efficiency for each panel is calculated and compared. The used material is PCM 47 with the following properties: melting point $=48^{\circ} \mathrm{C}$, melting range $=4 \Delta^{\circ} \mathrm{C}$, density $=$ $965 \mathrm{~kg} / \mathrm{m}^{3}$, latent heat $=194 \mathrm{~kJ} / \mathrm{kg}$, specific heat capacity $=1.68 \mathrm{~kJ} / \mathrm{kg} . \mathrm{K}$, Heat conductivity, perpendicular to compaction direction $=25 \mathrm{~W} / \mathrm{m} . \mathrm{K}$, Heat conductivity, parallel to compaction direction $=3$ $\mathrm{W} / \mathrm{m} . \mathrm{K}$. From the PV panel test at STC $\left(\mathrm{Ta}=25^{\circ} \mathrm{C}\right.$, $\mathrm{I}=1000 \mathrm{~W} / \mathrm{m}^{2}$ ) the efficiency is $15 \%$.

\section{Experimental SETUP}

The experimental setup used in this work consists of solar PV panels, inverter, controller, and batteries. The schematic diagram of the system is shown in Fig.1. The PV solar panels are Poly-crystalline, manufactured locally in Jordan, with rated power 175-watt. Panel dimensions are $1600 \mathrm{~mm} \times 800 \mathrm{~mm}$ and fixed on a tilted mountain structure. The charge controller used has a self-regulated ability; so when the batteries reach a full charge, the charging current is automatically reduced in order to prevent over-charging. DC/AC inverter was used to operate on an AC load. Several parameters are measured: global solar radiation was measure-using two solar meters, one is horizontal and the other one is tilted at the same angle of the PV panel, DC voltage and current output from the solar panel; temperatures of the ambient and the PV panels. Three thermocouples were fixed firmly to the back surface of the PV panel and two thermocouples were fixed to the glass surface of the solar panel. The wind speed was measured using an anemometer. When the PCM is applied, the temperature inside the PCM is measured. The data was collected using a data acquisition system.

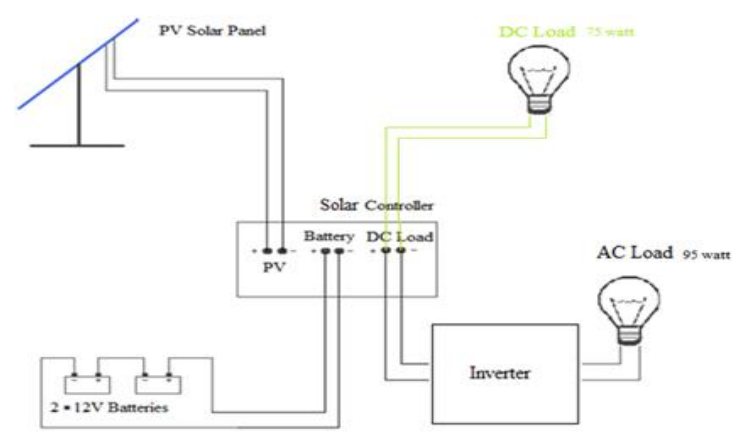

Fig. 1. Schematic diagram of the system set-up

\section{Mathematical formulations}

The mathematical models are built based on thermal resistance and energy balance concept. One model equations are for the PV without PCM and one with 
PCM. The PV panel efficiency is estimated using equations from Tonui and Tripanagnostopoulos [18]:

$\eta_{p v}=\eta_{r e f}\left(1-\delta\left(T_{p v}-T_{r e f}\right)\right)$

and

$$
\eta_{p v}=P_{\max } /_{A * G}
$$

Or another formula proposed by Notton et al. [19]:

$\eta_{p v}=\eta_{\text {ref }}\left\{1-\beta \Delta \theta+\gamma \log \left(\frac{G_{\beta}}{G_{\beta r e f}}\right)\right\}$

\subsection{Model equations for PV without PCM}

The energy Balance on the PV panel without PCM was established using the thermal resistance circuits shown in Fig. 2. The model equations are based on one dimensional and steady-state assumptions [20].

The energy balance gives :

$\tau_{g} \alpha_{P V} I-I \eta_{P V}=U_{T}\left(T_{P V}-T_{a}\right)$

$\eta_{P V}=\tau_{g} \alpha_{P V}-\frac{U_{T}}{I}\left(T_{P V}-T_{a}\right)$

The typical value of $\tau_{g} \alpha_{P V}$ is 0.9 . The overall heat transfer coefficient, $\mathrm{U}_{\mathrm{T}}$ is calculated using the resistance network shown in Fig. 2.

The linearized radiation heat transfer coefficient is

$h r_{g-a}=\varepsilon_{g} \sigma\left(T_{g}+T_{s}\right)\left(T_{g}{ }^{2}+T_{s}^{2}\right)$

$\mathrm{Ts}=\mathrm{Ta}-6\left({ }^{\circ} \mathrm{C}\right)$

The heat transfer convection coefficient at the top of the solar panel from Duffie [21] is

$h_{\text {convection }}=2.8+3 v$

Where $v$ is the wind speed $(\mathrm{m} / \mathrm{s})$. From Eq. 6 and Eq.8, it is easy to find $R_{\mathrm{g}-\mathrm{a}}$ as:

$R_{g-a}=\frac{1}{A\left(h_{\text {convection }}+h r_{g-a}\right)}$

Where $A$ is the area of the solar panel $\left(\mathrm{m}^{2}\right)$. The conduction heat transfer between the glass sheet and the cells sheet could be expressed as the following:

$R_{c-g}=\frac{\Delta x}{k_{\text {glass }} A}$

Where $\Delta x$ is the glass thickness (m), and $k_{\text {glass }}$ is the thermal conductivity of the glass. The conduction heat loss from the back panel surface, which is the same Eq. 10 but the thermal conductivity is of plastic.

$$
R_{c-b}=\frac{\Delta x_{b}}{k_{b} A}
$$

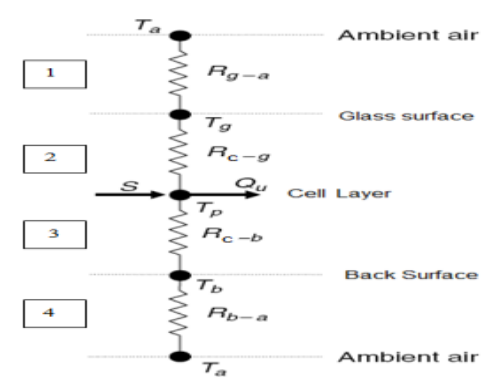

Fig. 2. PV Thermal circuit for the case of PV without PCM
The convection heat transfer between the back surface of the PV panel and the ambient temperature is calculated using Eqn. 4 and neglecting the radiation heat transfer from the back surface to ambient since it is relatively small. Thus,

$R_{b-a}=\frac{1}{A\left(h_{\text {convection }}\right)}$

$U_{T}=\frac{1}{R_{C-g}+R_{g-a}}+\frac{1}{R_{c-b}+R_{b-a}}$

Knowing that the glass thickness $\Delta x$ is $3.2 \mathrm{~mm}$ (from the manufacturer datasheet) and thermal conductivity of $k_{\text {glass }}=1.05 \mathrm{~W} / \mathrm{m} . \mathrm{K}$, back Tedlar sheet thickness is $\Delta x_{b}=2 \mathrm{~mm}$ with thermal conductivity of $k \cong 0.3 \mathrm{~W} / \mathrm{m} . \mathrm{K}$. Based on this data the thermal resistances are calculated and the overall heat transfer coefficient is estimated.

\subsection{Model equations for PV with PCM}

To formulate the energy balance equation on the PV with PCM, a control volume was assigned to the PV cell and the PCM, this control volume is shown in Fig. 3. The following assumption was used in the energy equation. First, the heat transfer coefficients from the front and back surfaces have a constant value of $h_{1}$ and $\mathrm{h}_{2}$. second, Heat dissipation from the top and bottom sides are relatively small, so it can be neglected. Third, the initial temperature of the PV panel equals the initial temperature of the PCM. Fourth, the temperature change to the PCM during a time of $\Delta t$ is $\mathrm{T}_{\mathrm{PV}}, \mathrm{t}+\mathrm{DT}$

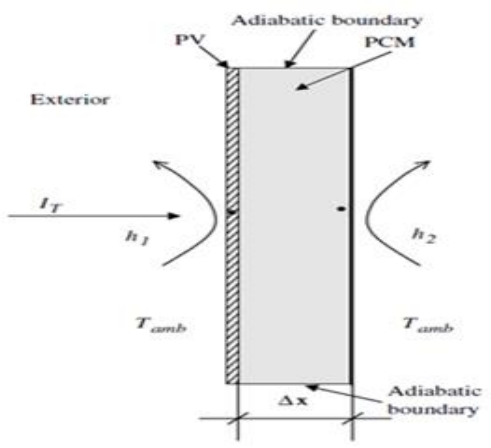

Fig. 3. Schematic diagram of the control volume for the PV panel with the presence of PMC [2]

The energy balance equation for the system when its temperature is less than the melting temperature $T_{m}$ of the PCM. It is assumed that the radiation losses and thermal resistance between the PCM and walls and between PCM and PV are neglected. Furthermore, no heat loss between the PCM and the surroundings.

$I_{T}\left(1-\eta_{P V, t}\right) \Delta t=\left(h_{1+} h_{2}\right)\left(T_{P V . t}-T_{a}\right) \Delta t+$

$\left(T_{P V, t+\Delta t}-T_{P V, t}\right) \rho c p \Delta x$

Where $A$ is the surface area $\left(\mathrm{m}^{2}\right), \mathrm{c}_{\mathrm{p}}$ is the specific heat $\left(\mathrm{J} \mathrm{kg}^{-1} \mathrm{~K}^{-1}\right), \mathrm{h}_{1}$ and $\mathrm{h}_{2}$ are the heat transfer coefficient $\left(\mathrm{Wm}^{-2} \mathrm{~K}^{-1}\right), \mathrm{T}_{\mathrm{a}}$ is the ambient temperature $\left({ }^{\circ} \mathrm{C}\right), \rho$ is the density $\left(\mathrm{kg} \mathrm{m}^{-3}\right)$. 
During the melting process of the PCM, if the temperature $T_{P V, t+\Delta t}$ is more than $\mathrm{T}_{\mathrm{m}}$, thermal energy is used and the PCM temperature will still at the same $T_{m}$ until the phase change is completed. The total time of the phase change is $\sum \Delta \mathrm{t}$ for which this condition holds. So, during the phase transition, the energy balance equation is:

$\sum I_{T}\left(1-\eta_{e l}\right) \Delta t=\sum\left(h_{1}+h_{2}\right)\left(T_{m}-T_{a m b}\right) \Delta t+\rho H \Delta x$

\section{Results and discussion}

The test was done in three phases; the first phase was done for three weeks without using the phase change material. The data was measured for several days from 7 am to $7 \mathrm{pm}$. The back temperatures are plotted in Fig. 4. It was found that the panel temperature was close to the ambient temperature. It reached the maximum value around 2:30 p.m., after that the temperature drops down with time.

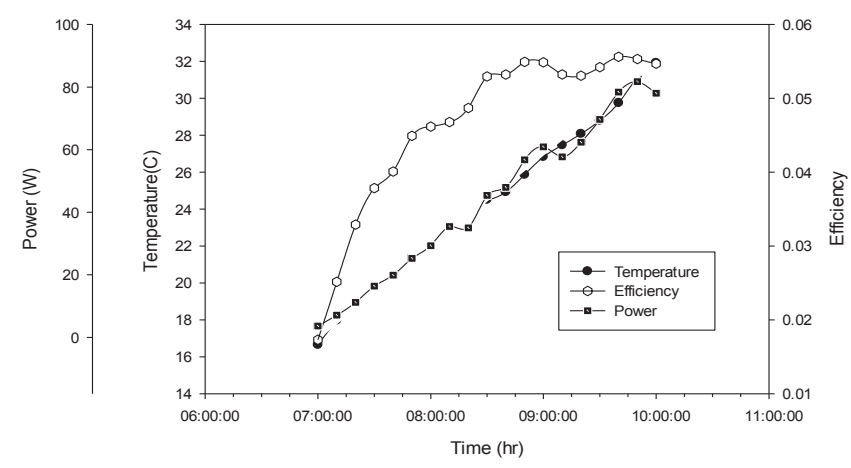

Fig. 4. Variation of temperature, power and theoretical system efficiency with time without PMC

The daily variation of the power output between 7:00 a.m. to 7:00 p.m. is shown on the same figure with the efficiency, Fig. 4. The figure shows that the average power output of the PV panel increases from zero, in the morning till, it reaches its maximum value around 11:30 am which is just before noon. Even though between $11: 30-12: 50$ p.m. the radiation is increasing, the power is gradual decreases. This is mainly due to the increase in cell temperature. To confirm this, Figure 6 shows the time variation of system efficiency during the day. The system efficiency was calculated using Eq. 2 based on measured values. Around noon, the efficiency before noon is higher than that afternoon through the values of the radiation and cosine losses are the same. The low values of the efficiency in the morning and afternoon are due to cosine losses.

Another set of measurements were taken without using the PCM in October. The instantaneous efficiency is calculated and plotted in Fig. 5. In this figure, the cosine losses were corrected based on the location and time. The value of the efficiencies was calculated based on the measured values. It is clear that the theoretical values are almost constant, while the measured values decrease afternoon. This behavior in the experimental values is mainly due to the increase in the cell temperature from heat stored in the system. This behavior cannot be detected from the theoretical model since it is built based on the steady-state analysis.

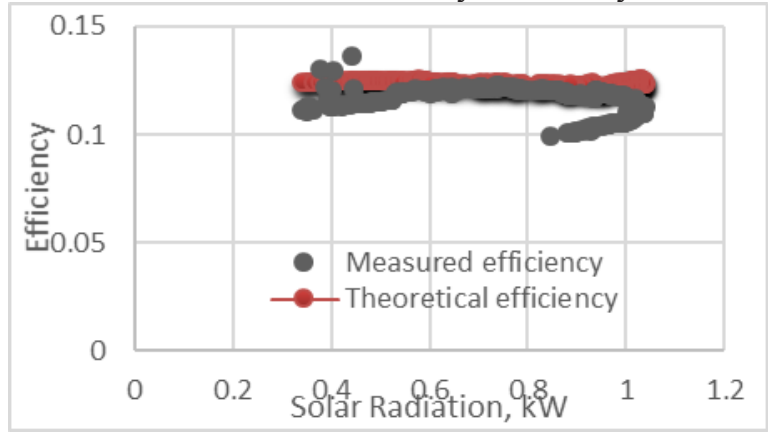

Fig. 5. Variation of measured and theoretical system efficiency with the solar irradiation without PCM

In Fig. 6, the PCM material was fixed on the back surface of the solar panel. The figure shows that the measured efficiency is much lower than the theoretical efficiency. This could be attributed to the fact that PV and the PCM temperature was below the PCM melting point. So the PCM worked as a thermal insulator. As it was discussed before, the melting temperature of the PCM used in this project was $47^{\circ} \mathrm{C}$, so it is predicted that it will behave better during the summer season.

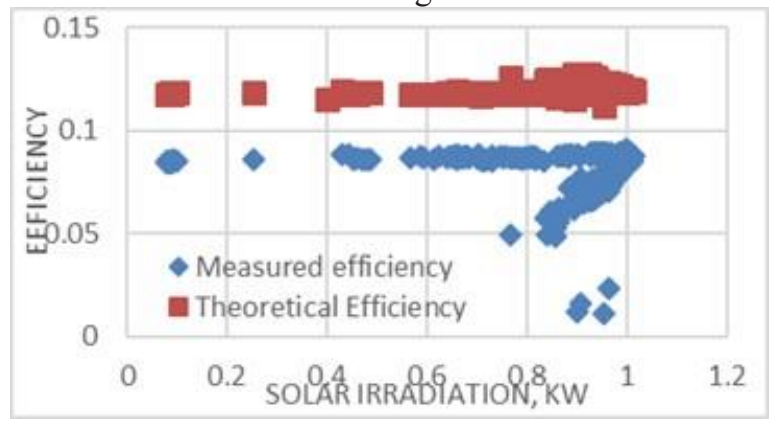

Fig. 6. Measured and theoretical efficiency with the radiation ratio with $\mathrm{PCM}$

The relation between the efficiency and the temperature ratio was plotted in Fig. 7. between 8:30 A.M. and 12:00 P.M., both efficiencies are increasing with the temperature ratio during morning hours because of low reflected energy losses and low initial cell temperature. The measured efficiency curve began to decrease after 12:00 pm in spite of that the solar irradiation is still at high levels between the period 12:00 pm - 2:00 pm, this sign explains the effect of the heat rise on the efficiency.

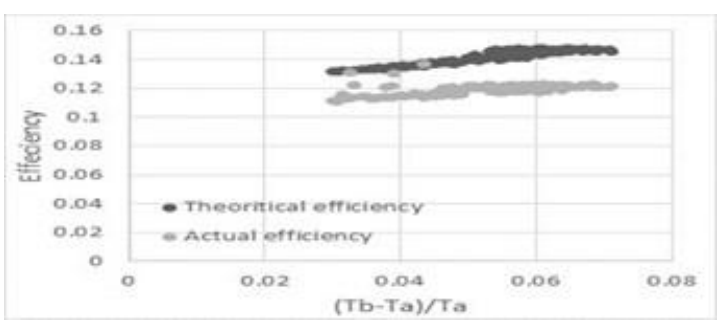


Fig. 7. Measured and theoretical efficiency with the temperature ratio with no PMC material installed (phase 2) for the period 8:30 A.M. until 12:00 P.M.

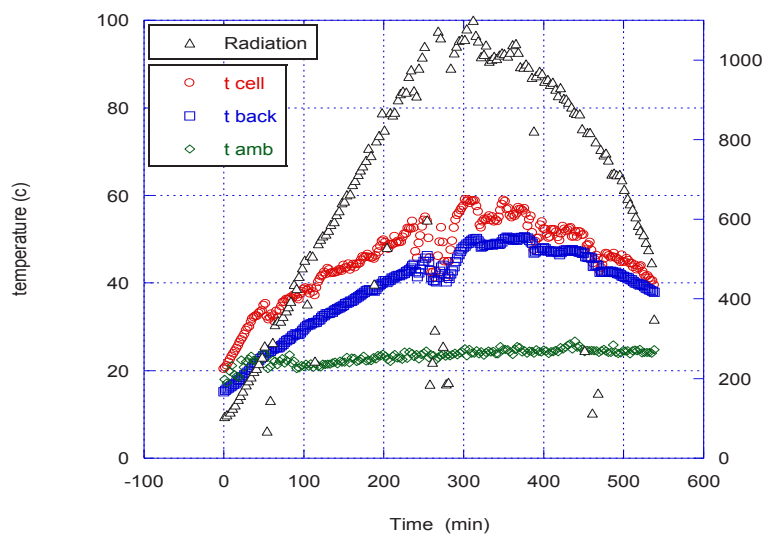

Fig. 8. Measured and theoretical efficiency with the radiation ratio with $\mathrm{PCM}$

Fig. 8 shows the variation of solar radiation, T_cell, $\mathrm{T}$ back and ambient temperatures during the testing day. Clouds caused scattered values of solar radiation. The temperature values were affected by the fluctuated solar radiation and that was between the $200-400 \mathrm{~min}$ of time. The measured panel efficiency for the same time period as Fig. 8 was plotted in Fig. 9. It was found that efficiency increased during the period of clouds' effects. That was because of the cell temperature decrease.

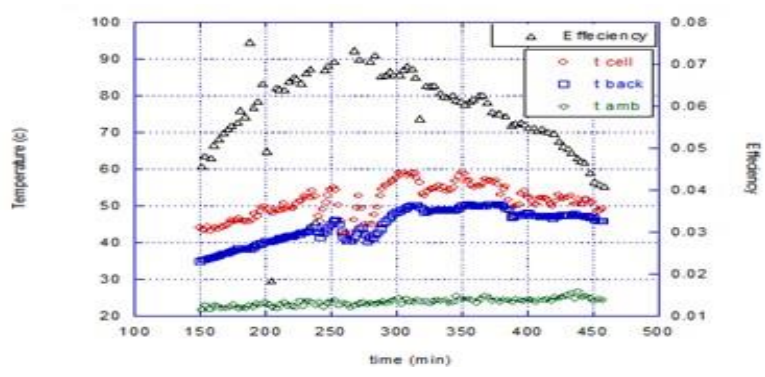

Fig. 9. The measured efficiency with the time and all temperature values of the test without PCM (phase 3)

Fig. 10 shows the efficiency versus radiation ratio before installing the PCM. This Figure shows almost the same trend as Fig. 5 but in Fig. 10, it is obvious that the behavior was different, although the measured and theoretical efficiencies readings are going parallel to each other for most of the day. This could be attributed to the changes in the operating conditions of high temperature.

Fig. 11 shows the efficiency measurements are collapsing between the range of $10 \%-12 \%$ during the noon period because the temperature of the back panel surface that day reached over $50{ }^{\circ} \mathrm{C}$. For the efficiency with temperature ratio relation, Fig. 12 shows the relation before installing the PCM for the period 8:30 am to $2: 30 \mathrm{pm}$. The efficiency with temperature ratio variation in Fig. 12 is behaving like Fig. 7 except some scattering data. Measured efficiency is ranging between $10 \%-12 \%$.

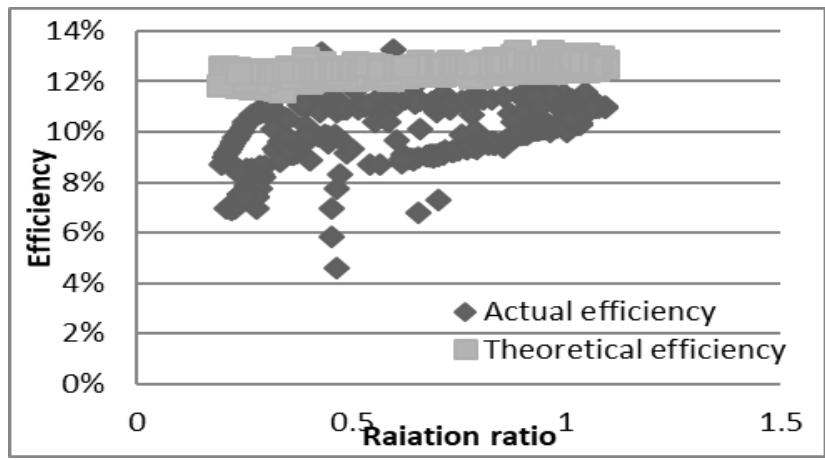

Fig. 10. Measured and theoretical efficiency with the radiation ratio without PCM material (phase 3)

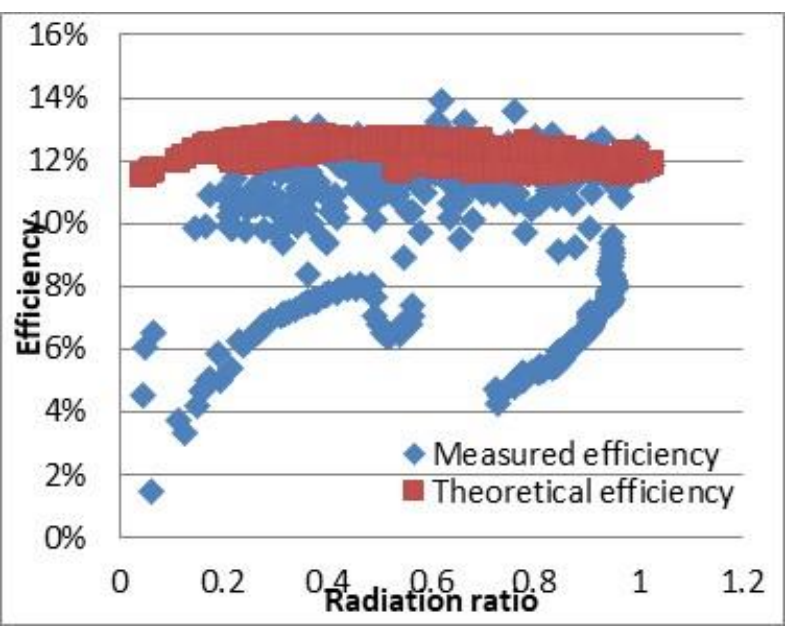

Fig. 11. Measured and theoretical efficiency with the radiation ratio with PCM material installed (phase 3) for the period 8:30 A.M. until 2:30 P.M.

The effect of PCM material on PV module, Fig. 12 shows that the efficiency is increased and also the difference between the measured and theoretical efficiency is less than before. On the other hand, the measured efficiency readings are showing better approaching the theoretical efficiency if compared in Fig. 13 and 14.

Fig. 13 and 14 are showing the behavior of efficiency and all measured temperatures and solar radiation. The PCM was present on that day but the temperature of the cell did not reach the melting point.

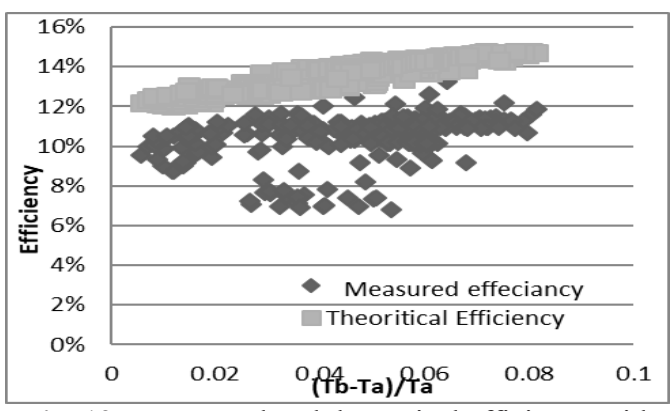

Fig. 12. Measured and theoretical efficiency with temperature ratio without PCM material (phase 3) 


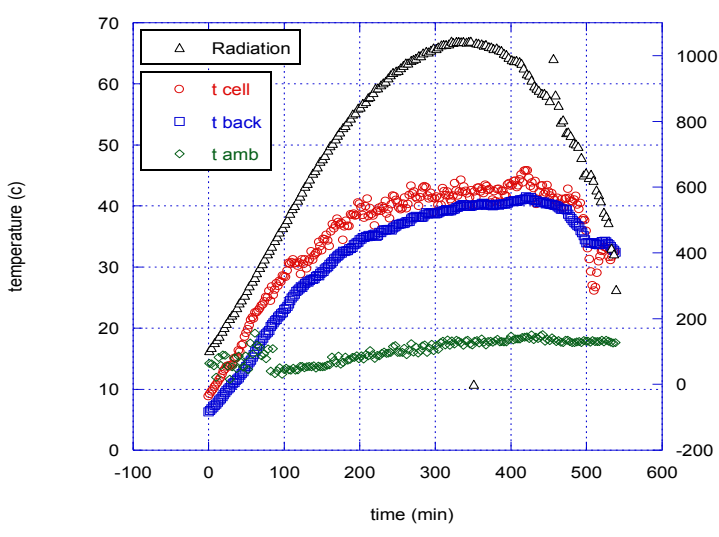

Fig. 13. The radiation with the time and all temperature values of the test with the presence of the PCM (no melting occurs)

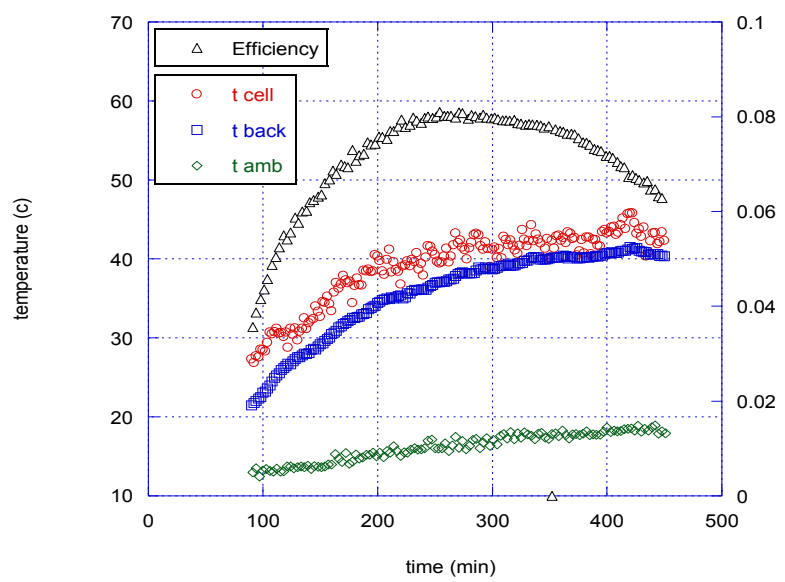

Fig. 14. The efficiency with the time and all temperature values of the test with the presence of PCM (no melting occurs)

\section{Conclusion}

The effect of the phase change material was investigated in this paper and it was found that the PCM material would give positive results only when the temperature of the panel exceeds the PCM melting point. On the other hand, If the temperature of the back panel is less than the melting temperature the PCM material will work exactly as an insulation material leading not to dissipate heat easily from the back surface of the solar panel. Following that, it is known that even when the weather is hot, the temperature will reach the maximum rise at noon, so, before and after this period the material will make a negative contribution to the system.

\begin{tabular}{ll} 
A & \multicolumn{1}{c}{ Nomenclature } \\
$\mathrm{c}_{\mathrm{p}}$ & is the PV surface area $\left(\mathrm{m}^{2}\right)$ \\
$\mathrm{G}$ & is the incident solar radiation $\left(\mathrm{W} \mathrm{m}^{-2}\right)$ \\
$G_{\beta}$ & is the solar radiation $\left(\mathrm{w} / \mathrm{m}^{2}\right)$ \\
$G_{\beta}$ ref & $\begin{array}{l}\text { is the solar radiation at reference conditions } \\
\left(\mathrm{w} / \mathrm{m}^{2}\right)\end{array}$ \\
$\mathrm{h}$ & heat transfer coefficient $\left(\mathrm{Wm}^{-2} \mathrm{~K}^{-1}\right)$
\end{tabular}

$h r_{g-a}$ the radiation heat transfer coefficient between the glass and the ambient

I the current output of the system (A)

$k_{\text {glass }}$ the thermal conductivity of the glass $\left(\mathrm{Wm}^{-1}\right.$ $\mathrm{K}^{-1}$ )

$\mathrm{S} \quad$ total energy incident (W)

$T_{g} \quad$ glass temperature $\left({ }^{\circ} \mathrm{C}\right)$

$T_{a} \quad$ ambient temperature $\left({ }^{\circ} \mathrm{C}\right)$

$T_{b} \quad$ Back temperature $\left({ }^{\circ} \mathrm{C}\right)$

$\mathrm{T}_{\mathrm{amb}} \quad$ ambient temperature $\left({ }^{\circ} \mathrm{C}\right)$

$\mathrm{U}_{\mathrm{L}} \quad$ overall heat transfer coefficient $\left(\mathrm{Wm}^{-2} \mathrm{~K}^{-1}\right)$

$\mathrm{V}$ the output voltage (V)

$\mathrm{V} \quad$ wind speed $(\mathrm{m} / \mathrm{s})$.

\section{Greek Symbols}

$\beta \quad$ constant (for silicon $=0.0048 \mathrm{C}^{-1}$ )

$\gamma \quad$ dimensionless constant (for silicon $=0.12$ )

$\Delta \theta \quad$ is $\left(\theta_{\text {cell }}-\theta_{\text {cell ref }}\right)\left({ }^{\circ} \mathrm{C}\right)$

$\delta \quad$ is the cell efficiency temperature coefficient that can be determined experimentally

$\varepsilon_{g} \quad$ is the emissivity of the glass $=0.85$

$\eta_{\text {ref }} \quad$ is the efficiency at reference conditions (from manufacturer table)

$\theta_{\text {cell }}$ is the temperature of the PV cells $\left({ }^{\circ} \mathrm{C}\right)$

害. $\theta_{\text {cell ref }}$ is the temperature of the PV cells at reference conditions

$\rho \quad$ the density $(\mathrm{kg} \mathrm{m}-3)$

$\sigma \quad$ is the Stefan-Boltzmann constant $=5.67 * 10^{-8}$ $\mathrm{w} / \mathrm{m}^{2}-\mathrm{k}^{4}$

\section{References}

1. A. Luque and S. Hegedus, Handbook of Photovoltaic Science and engineering. Spain. John Wiley. (2011)

2. Huang M.J., Eames P.C., Norton B., Phase change materials for limiting temperature rise in building integrated photovoltaics, Solar Energy, Vol 80 (9), P. 1121-1130, doi:10.1016/j.solener.2005.10.006.

(2006)

3. B. Brinkworth, Optimum depth for PV cooling ducts, Solar Energy, Vol. 80 (9), P. 1131-1134, doi:10.1016/j.solener.2005.09.006. (2006)

4. K. Park, G. Kang, H. Kim, G. Yu and J. Kim, Analysis of thermal and electrical performance of semi-transparent photovoltaic (PV) module; Energy, Vol. $35 \quad$ (6), P. 2681-2687, doi:10.1016/j.energy.2009.07.019. (2010)

5. G. Yun, M. McEvoy, and K. Steemers, Design and overall energy performance of a ventilated photovoltaic façade. Solar Energy, Vol. 81(3), P. 383-394. doi:10.1016/j.solener.2006.06.016 (2007)

6. C. Solanki, C. Sangani, D. Gunashekar and G. Antony, Enhanced heat dissipation of $\mathrm{V}$-trough modules for better performance, Solar Energy Materials and Solar Cells, Vol. 92 (12), P. 16341638, doi:10.1016/j.solmat.2008.07.022 (2008).

7. S. Krauter, Increased electrical yield via water flow over the front of photovoltaic panels, Solar Energy 
Materials and Solar Cells, Vol. 82 (1-2), P. 131-137, doi:10.1016/j.solmat.2004.01.011. (2004)

8. A. Kordzadeh, The effect of the nominal power of array and system head on the operation of photovoltaic water pumping set with array surface covered by a film of water, Renewable Energy, Vol. 35 (5), $\quad$ P. doi:10.1016/j.renene.2009.10.024. (2010)

9. M. Abdulzadeh and M. Ameri, Improving the effectiveness of a photovoltaic water pumping system by spraying water over the front of the photovoltaic cell, Renewable Energy, Vol. 34 (1), P. 91-96. doi:10.1016/j.renene.2008.03.024. (2009)

10. A. Alkhalidi, M.K. Khawaja, A. Kelany, and A. Ghaffar, "Investigation of Repurposed Material Utilization for Environmental Protection and Reduction of Overheat Power Losses in PV Panels." International Journal of Photoenergy 2019 (2019).

11. M. Al-Nimr, W. Al-Ammari, and A. Alkhalidi. "A novel hybrid photovoltaics/thermoelectric cooler distillation system." International Journal of Energy Research 43.2 (2019): 791-805.

12. L. Zhu, R. Boehm, Y. Wang, C. Halford and Y. Sun, Water immersion cooling of PV cells in a high concentration system, Solar Energy Materials and Solar Cells, Vol. 95 (2), P. 538-545, doi:10.1016/j.solmat.2010.08.037. (2011)

13. S. Kiwan, O. Zeitoun, and A. Alkhalidi. "Transient heat transfer for the cooling of PVC tubes using water jet." Experimental Thermal and Fluid Science 102 (2019): 539-547.

14. A. Alkhalidi, L. Qoaider, A. Khashman, A. AlAlami, and S. Jiryes "Energy and water as indicators for sustainable city site selection and design in Jordan using smart grid." Sustainable cities and society 37 (2018): 125-132.

15. N. Nader, W. Al-Kouz, S. Al-Dahidi. (2019). Assessment of Existing Photovoltaic System with Cooling and Cleaning System: Case Study at AlKhobar City. Processes, 8(1), 9. doi: 10.3390/pr8010009

16. W. Al-Kouz, S. Al-Dahidi, B. Hammad, M. AlAbed. (2019). Modeling and Analysis Framework for Investigating the Impact of Dust and Temperature on PV Systems' Performance and Optimum Cleaning Frequency. Applied Sciences, 9(7), 1397. doi: 10.3390/app9071397

17. A. Al-Bashir, M. Al-Dweri, A. Al-Ghandoor, B. Hammad, W. Al-Kouz. (2020). Analysis Of Effects Of Solar Irradiance, Cell Temperature And Wind Speed On Photovoltaic Systems Performance. International Journal of Energy Economics and Policy, 10(1), 353-359. doi: 10.32479/ijeep.8591

18. J. Tonui and Y. Tripanagnostopoulos, Improved $\mathrm{PV} / \mathrm{T}$ solar collectors with heat extraction by forced or natural air circulation, Renewable Energy, Vol. 4,
P. 623-637, doi:10.1016/j.renene.2006.03.006. (2007)

19. G. Notton, V. Lazarov and L. Stoyanov Optimal sizing of a grid-connected PV system for various PV module technologies and inclinations, inverter efficiency characteristics and locations. Renewable Energy, Vol. 35 (2), P. 541-554, doi:10.1016/j.renene.2009.07.013. (2010)

20. J. Kaldellis, M. Kapsali, K. Kavadias Temperature and wind speed impact on the efficiency of PV installations. Experience obtained from outdoor measurements in Greece", Renewable Energy 66 612-624 (2014)

21. A. Duffie and C. Beckman, A. Solar Engineering of Thermal Processes. New York. Wiley. ISBN: 9780-470-87366-3. (2013) 